\title{
Gold highlights on the 22nd Meeting of the Portuguese Society of Chemistry in Braga, Portugal, July 3-6, 2011
}

\author{
Sónia A. C. Carabineiro
}

Published online: 8 October 2011

(C) The Author(s) 2011. This article is published with open access at Springerlink.com

\section{Introduction}

There were around 600 participants attending this meeting, mostly native Portuguese and foreigners doing research in Portugal, coming from several chemistry areas. However, some participants from Spain, France, Germany, Austria, UK and Brazil were also present. The majority were from universities and research institutes; but some representatives from industry and secondary schools, including students, were also present. This year's conference was concerned with the ' 100 years of Chemistry in Portugal', celebrating the 100th anniversary of the Portuguese Society of Chemistry (Sociedade Portuguesa de Química, SPQ). It was a very special meeting since 2011 is also the International Year of Chemistry [1]. In spite the economic crisis felt in Portugal, this was the most attended SPQ meeting ever. Nowadays, chemistry is the area that originates more publications in Portugal, being above health and physics subjects, so said Prof. Mário Berberan Santos, president of SPQ, as reported in a local newspaper of Braga [2].

Gold-related subjects were represented by 2 plenary lectures (out of 11), 4 oral presentations (out of around 100) and 10 posters (out of around 350), which were much more than in the last meeting in 2008 ( 1 out of 50 orals and 8 out of 240 posters) [3], showing that Portugal's research on gold is increasing. A brief description is indicated below, by chemistry area.

S. A. C. Carabineiro $(\bowtie)$

Laboratory of Catalysis and Materials (LCM), Associate

Laboratory LSRE/LCM, Faculty of Engineering,

University of Porto,

Rua Dr. Roberto Frias, s/n,

4200-465 Porto, Portugal

e-mail: scarabin@fe.up.pt

\section{Physical chemistry}

Mehran Mostafavi (University of Paris South, France) gave a plenary lecture on 'Nanoparticles in solution-the contribution of radiation chemistry'. The speaker showed examples of $\mathrm{Au}, \mathrm{Ag}, \mathrm{Ni}, \mathrm{Pd}, \mathrm{Pt}$ metal clusters obtained by radiolysis, which has been proved to be a powerful method to synthesize homodisperse nanocolloids at room temperature and control their size $[4,5]$. A brief history of the clusters physical chemistry was also told. The one-pot synthesis of gold nanorods by radiolytic reduction of $\mathrm{Au}^{\text {III }}$ complexes using cationic surfactants (cetyltrimethylammonium bromide and tetraoctylammonium bromide) and in the presence of acetone and silver ions was referred. The colour can vary from red to blue, green and brown with increasing silver amount. It was shown that the nonlinear optical response (at $\lambda=532 \mathrm{~nm}$ ) of gold particles (with 2.5, 9 or $15 \mathrm{~nm}$ radius) is size-dependent [4]. Bimetallic alloyed clusters of Ag-Au, Au-Pd and Au-Pt that are of very high interest in catalysis were also referred $[6,7]$.

José Gomes (University of Aveiro) was one of the winners of the Vicente de Seabra Medal, which is attributed every 2 years to a less than 40-year-old researcher for the quality, originality and autonomy of his/her research work in chemistry carried out in Portugal, in memory of the pioneer Portuguese chemist Vicente Coelho de Seabra Silva Teles (1764-1804). In his lecture, entitled 'Exploring mechanisms of chemical reactions at surfaces', Gomes spoke about his work on density functional theory (DFT) calculations on several crystal surfaces, namely on gold. His work includes DFT studies on gold surfaces, e.g. $\mathrm{Au}(321)$ or $\mathrm{Au}(111)$, shown in Fig. 1, for $\mathrm{CO}$ oxidation, adsorption of atomic and molecular oxygen, NO dissociation and oxidation, water adsorption and dissociation. 
Fig. $1 \mathrm{Au}(111)$ (left) and $\mathrm{Au}$ (321) (right) surfaces (generated with Surface Explorer [8])
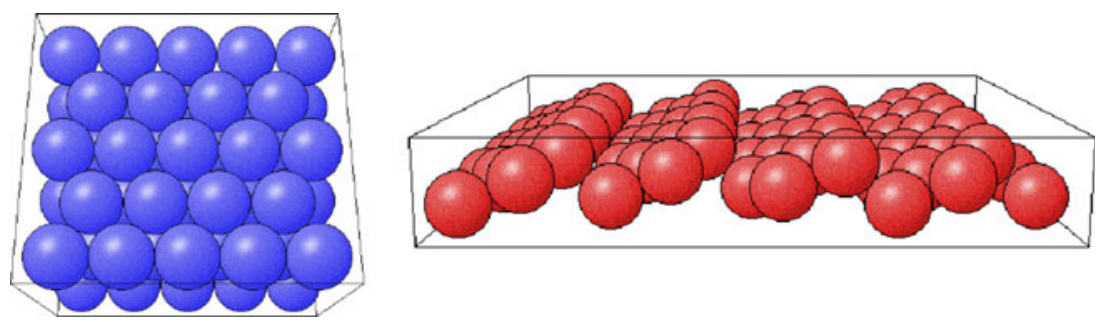

José Gomes also presented a poster 'On the theoretical understanding of the unexpected $\mathrm{O}_{2}$ activation by nanoporous gold'. It was recently discovered that nanoporous gold has a high activity in several oxidation reactions and some authors believe that the unexpected activation of $\mathrm{O}_{2}$ by the nanoporous gold must be related with the residual silver present in the catalyst [9]. Gomes and co-workers made a DFT study on the adsorption and dissociation of $\mathrm{O}_{2}$ on different pure gold, pure silver and silver doped gold surfaces, showing that residual $\mathrm{Ag}$ on $\mathrm{Au}$ is indeed able to promote adsorption and to dissociate thermodynamically favourable $\mathrm{O}_{2}$, with high rate constants. The activation probably occurs on Ag particles or rows deposited on $\mathrm{Au}$ or on corrugated Au surfaces with a few incrustrated Ag atoms [10].

Jorge Morgado (Technical University of Lisbon) spoke about 'Fabrication of molecular wires by scanning tunneling microscopy (STM) controlled self-assembly', using highly ordered pyrolytic graphite as substrate, a zinc(II) porphirin and a bipyridine as building blocks. The process of wire growing was monitored step by step using STM and the electrical characterisation was carried out by atomic force microscopy. Gold electrodes were used in this work.

João Lima (New University of Lisbon) spoke about 'Photophysical characterization of fluorophores on the vicinity of gold nanoparticles'. As metal nanoparticles (NPs) are known to change the optical properties of molecules near the metal surface, these authors demonstrated that the use of reference fluorophores can circumvent that fact and the relative fluorescence quantum yield of those fluorophores can be determined by using an alternative model to rationalize the observed fluorescence enhancement, which results from the increase of the effectual light scattered from the Au NPs surface that reaches the fluorophore and precludes the determination of the real radiative rate constant of fluorophores in the vicinity of NPs.

Artur Moro (New University of Lisbon) had a poster on 'Metal-enhanced photochemistry: how metal colloids improve photochemical reactions through near field enhancement effect'. Molecules of interest can be biologically inactivated (caged) by chemical modification with a protecting group, which can be eventually removed with light by irradiation of a suitable wavelength. These authors developed a highly efficient and biocompatible method for the controlled release of caged molecules (adenosine-5'triphosphate (ATP), a multifunctional nucleotide used in cells as a coenzyme, caged with [7-(diethylamino)coumarin-4-yl]methyl) (DEACM), with potential applications in DNA/RNA manipulation and synthesis, as well as intracellular drug release, using gold NPs (Scheme 1), that have excellent characteristics as nanoantennas, inducing strong fluorescence enhancement on emitters in their near field. Without $\mathrm{Au}$ NPs, the decaging process presented low efficiency and formation of bi-products, which produced inhibitory effects in the polymerization process of nucleic acid.

Sónia Carabineiro (University of Porto) presented a poster on 'Gold supported on $\mathrm{Cu}, \mathrm{La}, \mathrm{Ni}$ and $\mathrm{Y}$ oxides for CO oxidation'. Au was deposited by double impregnation (DIM), liquid-phase reductive deposition (LPRD) and ultrasonication methods [11]. The best results were obtained with Au loaded by DIM on the NiO support. This is most likely related to the Au nanoparticle size being the smallest in this catalyst (average $4.8 \mathrm{~nm}$ ). Other samples, having larger $\mathrm{Au}$ particle sizes, showed lower activities (Fig. 2). Nevertheless, all samples prepared by DIM had activities above those reported in the literature for gold on similar oxide supports, showing that this method gives better results than the most usual methods of depositionprecipitation or co-precipitation for $\mathrm{CuO}, \mathrm{La}_{2} \mathrm{O}_{3}, \mathrm{NiO}$ and $\mathrm{Y}_{2} \mathrm{O}_{3}$ supports.

Adrián Silva (University of Porto) presented a poster on 'Gold supported in $\mathrm{Ce}-\mathrm{Mn}-\mathrm{O}$ composite materials for the oxidation of CO', with different $\mathrm{Ce} / \mathrm{Mn}$ ratios and loaded with $\mathrm{Au}$ by DIM [11]. $\mathrm{CeO}_{2}$ and $\mathrm{Mn}_{3} \mathrm{O}_{4}$ were detected by XRD. The BET surface areas increase by addition of Mn or $\mathrm{Ce}$, respectively, with a maximum for molar percentages of $\mathrm{Ce}$ and $\mathrm{Mn}$ of $50 \%$. The higher the amount of ceria in the sample, the most active it was for $\mathrm{CO}$ oxidation. The ability to convert $\mathrm{CO}$ seems to be independent of the surface area of the supports, but for samples loaded with gold seems to vary with the temperature of the first reduction peak of the TPR spectra and the Au nanoparticle size.

Elisa Pereira (University of Porto) presented a poster on a 'DNA biosensor based on electropolymerised gold nanoparticle films', where gold NPs of $30 \mathrm{~nm}$ average were embedded into poly-Lysine (p-Lys) film though electro- 

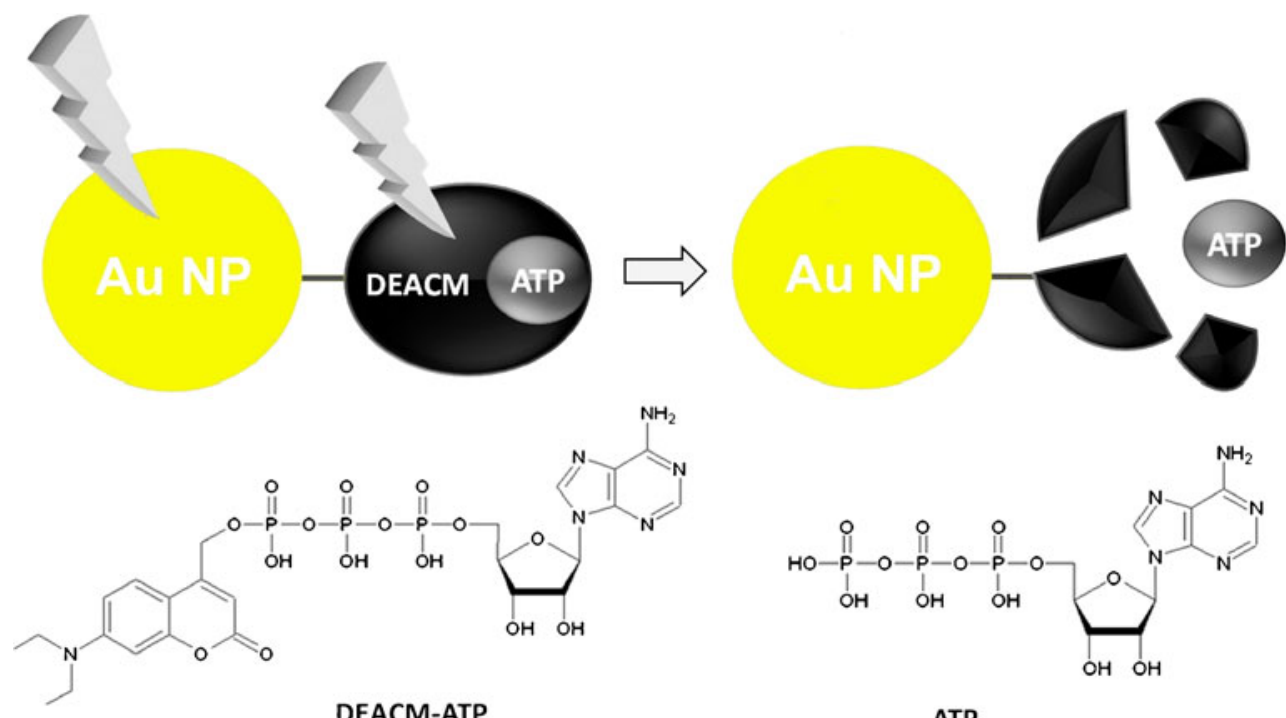

ATP

Scheme 1 Top: Au NPs enhanced decaging effect of ATP by light irradiation (redrawn from the abstract). Bottom: Structure of ATP alone (left) or linked to DEACM

chemical polymerization on glassy carbon electrodes (GC). Cyclic voltammetry studies showed that the highest peak currents were recorded at GC/p-Lys-AuNP modified electrodes containing low amounts of Au NPs. DNA double strand was self-assembled on this film and electrochemically studied using the same redox probes. Therefore, DNA functionalised GC/p-Lys-AuNP modified electrodes could be used as biosensors for actinomycin D (Scheme 2) detection, which is a chemotherapy drug, commonly used for many years in treatment of a variety of cancers, also a highly toxic antibiotic for humans, as it causes damage to genetic material.

Elodie Rodrigues (University of Porto) presented a poster on 'Selective oxidation of glycerol catalysed by gold supported on multiwalled carbon nanotubes (MWCNTs). Samples were prepared by several techniques like DIM and LPRD [11], reduction with nitric acid [12] and sol immobilisation method [13]. The latter lead to the

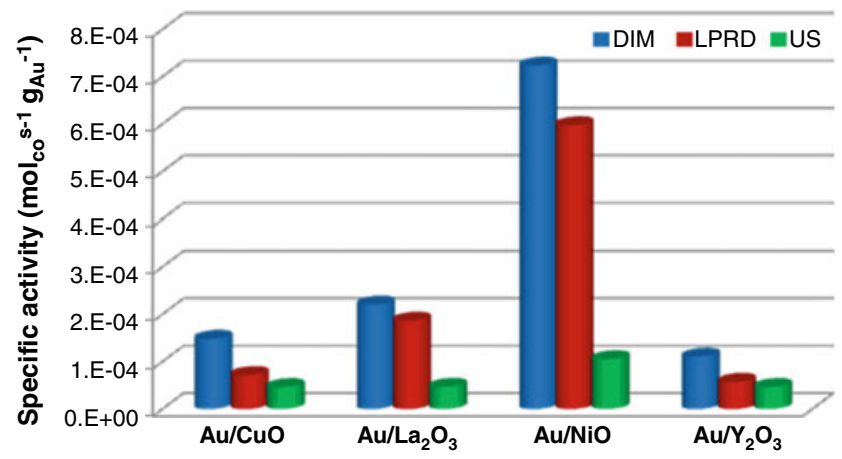

Fig. 2 Specific activities for the different Au/oxide catalysts determined at room temperature, prepared by different methods (adapted from [11]) best results, as reported in literature for Au-activated carbon (AC) catalysts [14]. The activity of the Au/MWCNTs was not significantly different from $\mathrm{Au} / \mathrm{AC}$; however, the distribution of the main products (dihydroxyacetone and glyceric acid, Scheme 3) was practically reversed; as selectivities to dihydroxyacetone of around 60\% were observed over Au/MWCNT catalysts, which is a very important significant result, considering the high value of this compound.

\section{Organic chemistry}

André Lopes (University of Porto) presented a poster on 'Selective oxidation of renewable organic substrates by gold supported on carbon materials'. Using molecular oxygen, arabinoic acid could be synthesised from arabinose, D-arabino-1,4-lactone being found as an intermediary (Scheme 4). Preliminary results showed that MWCNTs

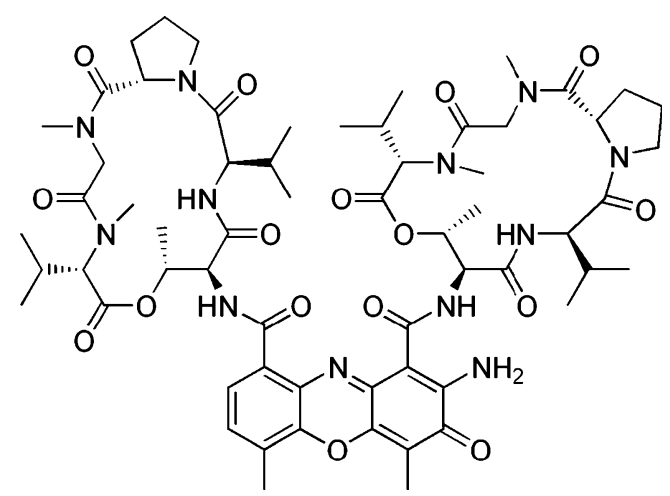

Scheme 2 Actinomycin D structure 
Scheme 3 Selective oxidation of glycerol into dihydroxyacetone and glyceric acid

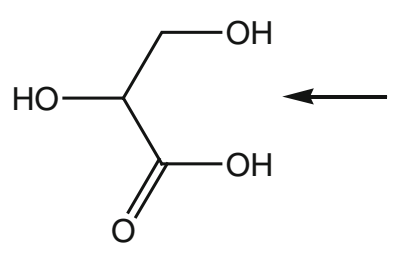

glyceric acid

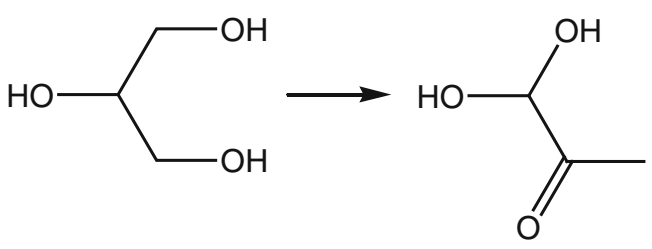

glycerol

dihydroxyacetone
(Nanocyl-NC3100) and carbon xerogel (CX, prepared by the resorcinol/formaldehyde approach [15]), loaded with 1 wt.\% Au (by the sol method [13]) were used as catalysts. $\mathrm{Au} / \mathrm{CNT}$ was less active than $\mathrm{Au} / \mathrm{CX}$. Further research is currently being done for optimization of results and characterisation of samples.

\section{Analytical chemistry}

Susana Ribeiro (Institute of Engineering of Porto) spoke about the development of an 'Electrochemical biosensor based on tyrosinase immobilized on 3D gold nanoelectrode ensembles for the determination of L-DOPA (L-3,4-dihydroxyphenylalanine, a naturally occurring dietary supplement and psychoactive drug found in certain kinds of food and herbs, used in the clinical treatment of Parkinson's disease and dopamine-responsive dystonia, and a precursor to the biological pigment melanin). The tyrosinase enzyme was immobilized on the gold nanoelectrode, which was prepared by chemical etching [16] and the detection limit was $1 \times 10^{-9} \mathrm{~mol} / \mathrm{L}$ in L-DOPA-spiked serum samples, of which $83 \%$ could be recovered.

Georgina Alves (University of Porto) spoke about a simple, fast, innovative, reliable and cheap method for 'Simultaneous electrochemical determination of arsenic, copper, lead and mercury ions, at trace levels, using a vibrating gold microwire electrode', as an alternative to toxic $\mathrm{Hg}$ electrodes. The combination of a vibrator with a gold microwire electrode resulted in very small diffusion layer thickness (less than $1 \mu \mathrm{m}$ ) which improves the sensitivity and the reproducibility of results. Well-defined, undistorced, sharp and reproducible peaks for trace concentrations of those ions were found. The detection limits obtained for $\mathrm{As}, \mathrm{Cu}, \mathrm{Hg}$ and $\mathrm{Pb}$ were $0.068,0.40,0.018$ and $0.15 \mu \mathrm{g} / \mathrm{L}$, respectively. The method was successfully applied to the simultaneous determination of those four metals in unpolluted river water samples and results were validated by atomic absorption spectroscopy with electrothermal atomization or by inductively coupled mass spectroscopy.

Renata Costa (University of Porto) had a poster dealing with 'Electric double layer at the gold/binary ionic liquid mixtures'. Potential curves were determined for a gold electrode in contact with mixtures of room-temperature ionic liquids having two cations of the same homologous series and a common ion: 1-ethyl-3-methylimidazolium and 1-hexyl-3-methylimidazolium bis(trifluoromethylsulfonyl) imide. Results showed that there is preferential adsorption of the ethyl group on the gold surface.

\section{Inorganic chemistry}

Miguel Ferreira (University of Minho) presented a poster on 'Synthesis, characterization and relaxometric evaluation of gold nanoparticles functionalized with $\mathrm{Gd}^{+}$chelates as Magnetic Resonance Imaging contrast agents', explaining that $\mathrm{Au}$ NPs are promising platforms for the development of molecular imaging and therapeutic agents, since they are stable in physiologic conditions and biocompatible, providing a high-density surface clustering of reports and targeting vectors. Since the $\mathrm{Au}-\mathrm{S}$ bond is very stable, the use of bifunctional thiols for stabilizing and functionalizing
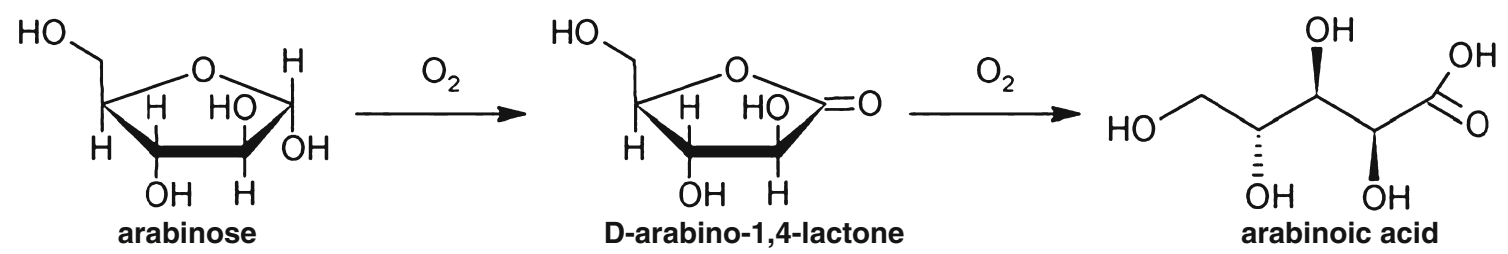

Scheme 4 Selective oxidation of arabinose into D-arabino-1,4-lactone and arabinoic acid using molecular oxygen 
<smiles>O=C(O)CN1CCN(CC(=O)O)CCN(CC(NC(=O)CCCCC2CCSS2)C(=O)O)CCN(CC(=O)O)CC1</smiles>

DОАЗА- $N$-(a-lipoamido)proprionate (1)<smiles>NC(CS)C(=O)NC(CNCN1CCN(CC(=O)O)CCN(CC(=O)O)CC1)C(=O)O</smiles>

DOA3A- $\mathrm{N}$-(a-cysteinamido)proprionate (2)

Scheme 5 DO3A (1,4,7,10-tetraazacyclododecane-1,4,7-triacetic acid) macrocyclic ligand-based metal chelators (adapted from the abstract)

gold nanoparticles. Authors synthesised novel metal chelators 1 and 2 (Scheme 5) for functionalizing Au NPs with $\mathrm{Gd}^{3+}$ chelates.

Márcia Ventura (New University of Lisbon) presented a poster on 'Studies on the synthesis of nanoparticles for the coloration of glasses regarding its application in decorative and artistic fields'. Authors produced coloured glasses based on the synthesis of gold and silver nanoparticles by a sol-gel method and by layer-by-layer deposition of polyelectrolytes to art works. Au and Ag NPs were used separately or as a mixture by varying their molar fractions, in order to obtain yellow, orange and red colours, and the processes were optimized in order to intensify the colours. Temperatures near the glass transition point were used during thermal treatment in order to fix the nanoparticles and, hence, the colour of the glass surface.

Acknowledgements I am grateful to Prof. Mehran Mostafavi for providing me the slides of his plenary lecture. Fundação para a Ciência e Tecnologia (FCT) is acknowledged (CIENCIA 2007 programme and project PTDC/QUI-QUI/100682/2008, financed by FCT and FEDER in the context of Programme COMPETE).
Open Access This article is distributed under the terms of the Creative Commons Attribution License which permits any use, distribution and reproduction in any medium, provided the original author(s) and source are credited.

\section{References}

1. http://www.chemistry2011.org/

2. Silva JP, Correio do Minho, 6 July 2011, page 8. Online version available at http://www.correiodominho.com/noticias.php? id $=50416$ (text in portuguese)

3. Carabineiro SAC (2008) Conference Report: Gold Highlights at the 21st Meeting of the Portuguese Society of Chemistry in Porto, Portugal, June 11-13, 2008. Gold Bull 41:350-351

4. François L, Mostafavi M, Belloni J, Delouis J-F, Delaire J, Feneyrou P (2000) Optical limitation induced by gold clusters. 1. Size effect. J Phys Chem B 104:6133-6137

5. Dey GR, El Omar AK, Jacob JA, Mostafavi M, Belloni J (2011) Mechanism of trivalent gold reduction and reactivity of transient divalent and monovalent gold ions studied by gamma and pulse radiolysis. J Phys Chem A 115:383-391

6. Treguer M, de Cointet C, Remita H, Khatouri J, Mostafavi M, Amblard J, Belloni J, de Keyzer R (1998) Dose rate effects on radiolytic synthesis of gold-silver bimetallic clusters in solution. $\mathrm{J}$ Phys Chem B 102:4310-4321

7. Redjala T, Remita H, Apostolescu G, Mostafavi M, Thomazeau C, Uzio D (2006) Bimetallic Au-Pd and Ag-Pd clusters synthesised by gamma or electron beam radiolysis and study of the reactivity/ structure relationships in the selective hydrogenation of buta-1,3diene. Oil \& Gas Sci Technol-Rev IFP 61:789-797

8. http://surfexp.fhi-berlin.mpg.de/SXinput.html

9. Wittstock AA, Zielasek V, Biener J, Friend CM, Bäumer M (2000) Nanoporous gold catalysts for selective gas-phase oxidative coupling of methanol at low temperature. Science 327:319-322

10. Fajin JLC, Cordeiro MNDS, Gomes JRB (2011) On the theoretical understanding of the unexpected $\mathrm{O}_{2}$ activation by nanoporous gold. Chem Commun 47:8403-8405

11. Carabineiro SAC, Bogdanchikova N, Avalos-Borja M, Pestryakov A, Tavares PB, Figueiredo JL (2011) Gold supported on metal oxides for carbon monoxide oxidation. NanoResearch 4:180-193

12. Zanella R, Basiuk EV, Santiago P, Basiuk VA, Mireles E, PuenteLee I, Saniger JM (2005) Deposition of gold nanoparticles onto thiol-functionalized multiwalled carbon nanotubes. J Phys Chem B 109:16290-16295

13. Onal Y, Schimpf S, Claus P (2004) Structure sensitivity and kinetics of D-glucose oxidation to D-gluconic acid over carbonsupported gold catalysts. J Catal 223:122-133

14. Porta F, Prati L, Rossi M, Coluccia S, Martra G (2000) Metal sols as a useful tool for heterogeneous gold catalyst preparation: reinvestigation of a liquid phase oxidation. Catal Today 61:165-172

15. Mahata N, Pereira MFR, Suárez-García F, Martínez-Alonso A, Tascón JMD, Figueiredo JL (2008) Tuning of texture and surface chemistry of carbon xerogels. J Colloid Interf Sci 324:150-155

16. Krishnamoorthy K, Zoski CG (2005) Fabrication of 3D gold nanoelectrode ensembles by chemical etching. Anal Chem 77:5068-5071 